\title{
Prosthetic Rehabilitation of an Ocular Defect by Custom Eye Prosthesis: A Clinical Report
}

\author{
Basnet BB* , Singh RK \\ Department of Prosthodontics, B. P. Koirala Institute of Health Sciences, Dharan \\ *Corresponding author: bishal_bpkihs@yahoo.com
}

Received September 23, 2014; Revised October 13; Accepted October 15, 2014

\begin{abstract}
The defects of eye due to trauma or surgical procedure can result in grievous psychological injury to the patient. The defect can range from an enucleated to an exenterated eye. With properly fabricated custom prosthesis the patient can return to an optimal normalcy in social and psychological aspects. Case details: A 58-year-old female presented with an enucleated eye. After examination, an impression made with elastomeric impression material and it was changed to sclera blank made from wax. An iris obtained from an eye conformer was attached to the waxed pattern, which was invested in a flask after trial in the socket. With acrylic resin of matching color final prosthesis was fabricated. Conclusion: With meticulous impression of socket and customization of iris the cosmetic demands of patient can be fulfilled and thus mitigate social and psychological trauma to the patient.
\end{abstract}

Keywords: enucleation, custom ocular prosthesis, conformer

Cite This Article: Basnet BB, and Singh RK, "Prosthetic Rehabilitation of an Ocular Defect by Custom Eye Prosthesis: A Clinical Report.” International Journal of Dental Sciences and Research, vol. 2, no. 5 (2014): 115119. doi: 10.12691/ijdsr-2-5-4.

\section{Introduction}

Defects of eye may cause enormous social and psychological trauma to the patient. The defect can range from en bloc removal of entire orbit, known as exenteration to removal of only eyeball, known as enucleation. [1-7] Enucleation is removal of entire globe, including the cornea, sclera and a portion of optic nerve. The rehabilitation of such eyes can be relatively easy if an impression of socket is made properly. Exenteration, on the other hand, refers to a radical procedure removing the globe as well as the complete or partial removal of the soft tissues of the orbit. The prosthesis in exenterated cases can not be retained like the former, so other retentive means such as spectacle, magnetic buttons, adhesive, pin and sockets etc are needed.

Major causes of defects include trauma, tumors and congenital anomalies. [3,6,9] The prosthetic eye can accomplish relief to the psychologically handicapped patients to some extent. A multidisciplinary efforts from a prosthodontist, an opthalomologist, a surgeon and a maxillofacial prosthetist is needed for successful outcome. $[2,4,5,6]$ An ocular prosthesis which gives attention to the accurate duplication of color, contour, size and ocular orientation as those of natural eye is paramount for providing natural realism and symmetry [8].

This case report describes fabrication of an ocular prosthesis in a simplified approach with minimally available materials and techniques for natural appearance of a patient.

\section{Case Report}

A 58-year-old lady presented to Department of Prosthodontics, B. P. Koirala Institute of Health Sciences, Dharan, Nepal with an enucleated eye socket (Figure 1). She had defect on her left eye some 10 years back but she was unknown to treatment modality for cosmetic purpose and was wearing black spectacle to hide her eyes leading to social discomfort. On examination the socket was free of active inflammation, stump was mobile, and there was no need for further surgery. She was described about the steps, cost, limitations and scope of prosthetic eye. She opted for custom eye prosthesis.

\section{Procedure}

\section{Selection of conformer}

A stock eye was obtained from Ophthalmology department which matched the color of her remaining eye. 2. Impression

An impression was made with light-bodied silicone material injected from a syringe. The patient was asked to gaze at a curtain placed at 6 metre distance with relaxed facial muscles. The material was slowly filled into the socket while an assistant helped to retract the eyelids. The syringe was not pulled apart so as to make it help for retrieval (Figure 2). The impression was gently removed after material was set, the lower eyelid was massaged downward and away from the nose first and sliding away 
the impression out from the upper eyelid. It was disinfected and examined for any inaccuracy.

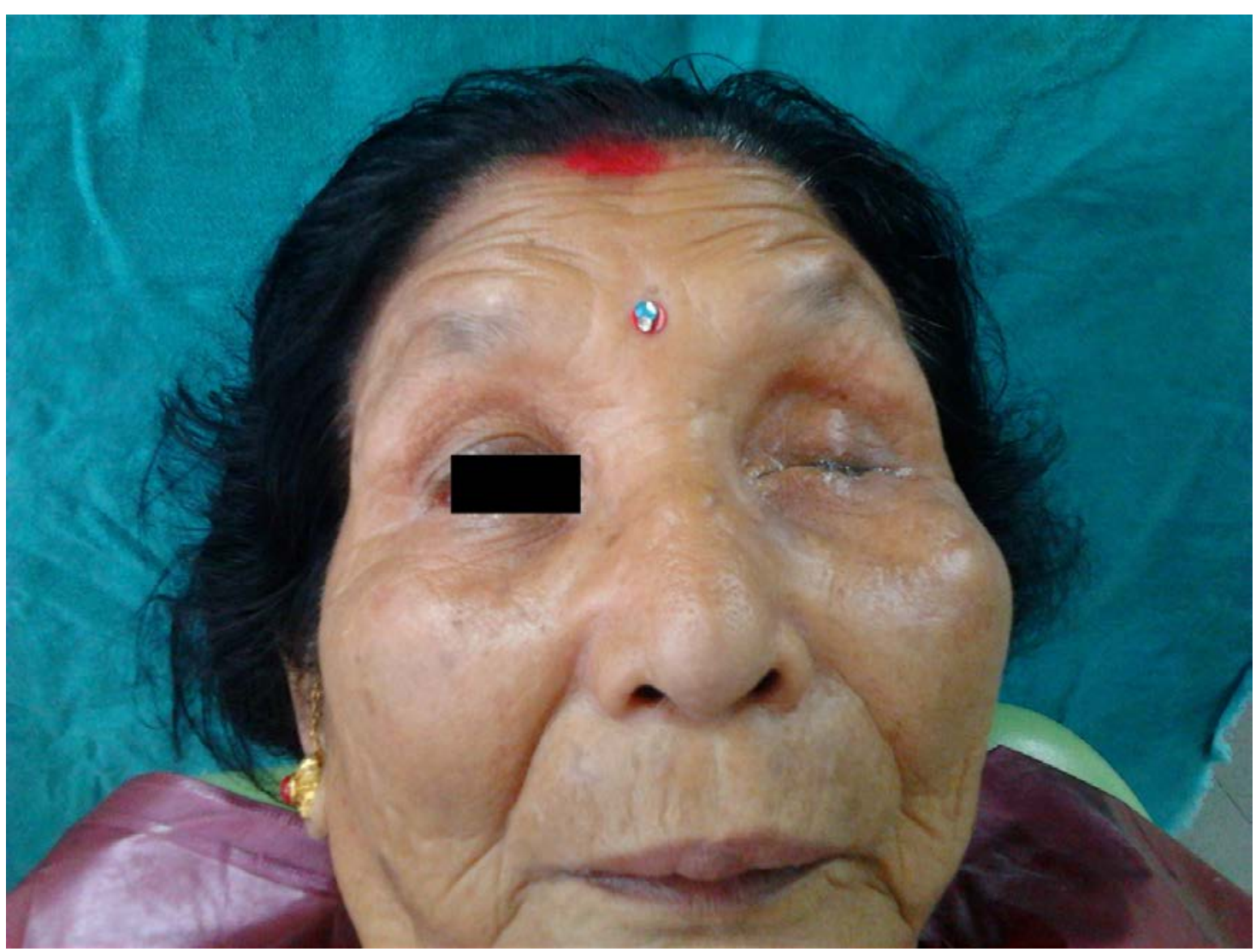

Figure 1. The defect of the left eye

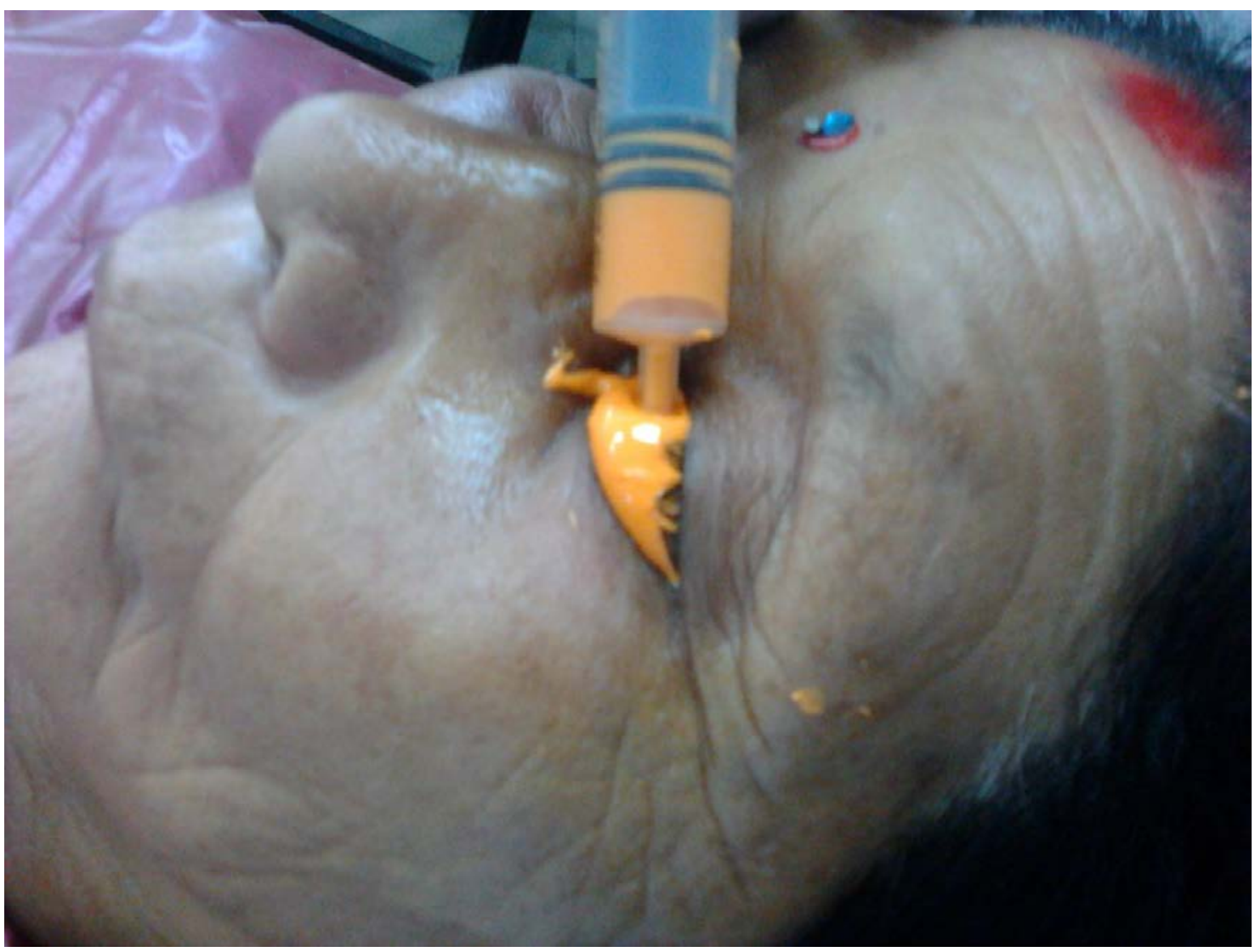

Figure 2. Impression made with light-bodied silicone impression material

\section{Preparation of stone mold}

A round box was made with modeling wax. On the box the type IV die stone was poured up to half part. The impression was dipped into the stone while it was not fully set. The impression was covered half part only. After application of separating medium, stone was again poured. A hole was drilled into the upper portion of set stone. 4. Preparation of wax conformer 
The mold was separated, the impression was removed. The mold was closed and the molten wax was poured from the hole that was drilled in one part of mold. After the wax was set, the mold was broken apart and wax conformer was taken out. It was evaluated for any discrepancy.

5. Trial of wax conformer

The wax pattern was placed into the socket and examined for its fit, retention, movement and support to the eyelids. Modifications were done with removal or addition of wax to defective area. After it was found to be suitable for patient and her husband, the marking of pupil and iris was done. For this a tissue tape was used to mark the intercanthal distance, distance from pupil of healthy eye to midline of nose etc. (Figure 4). The probable position of iris and pupil was marked over the wax pattern.

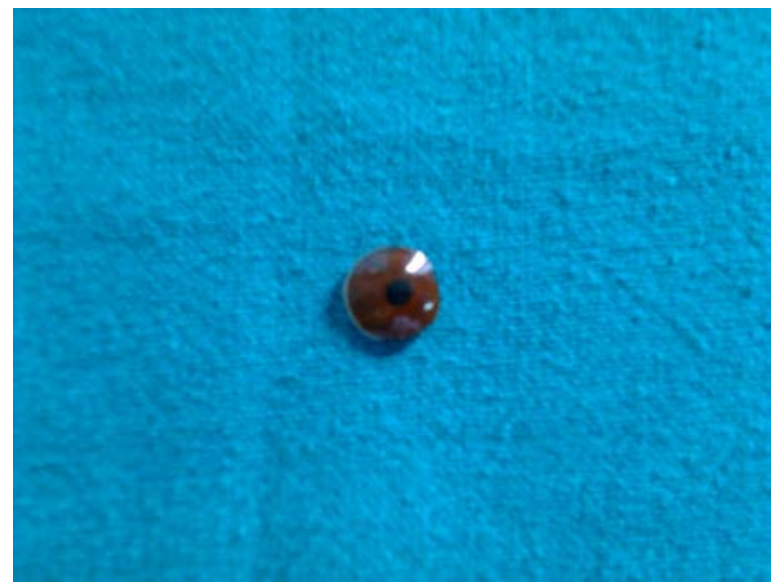

Figure 3. Iris part trimmed from a stock eye conformer

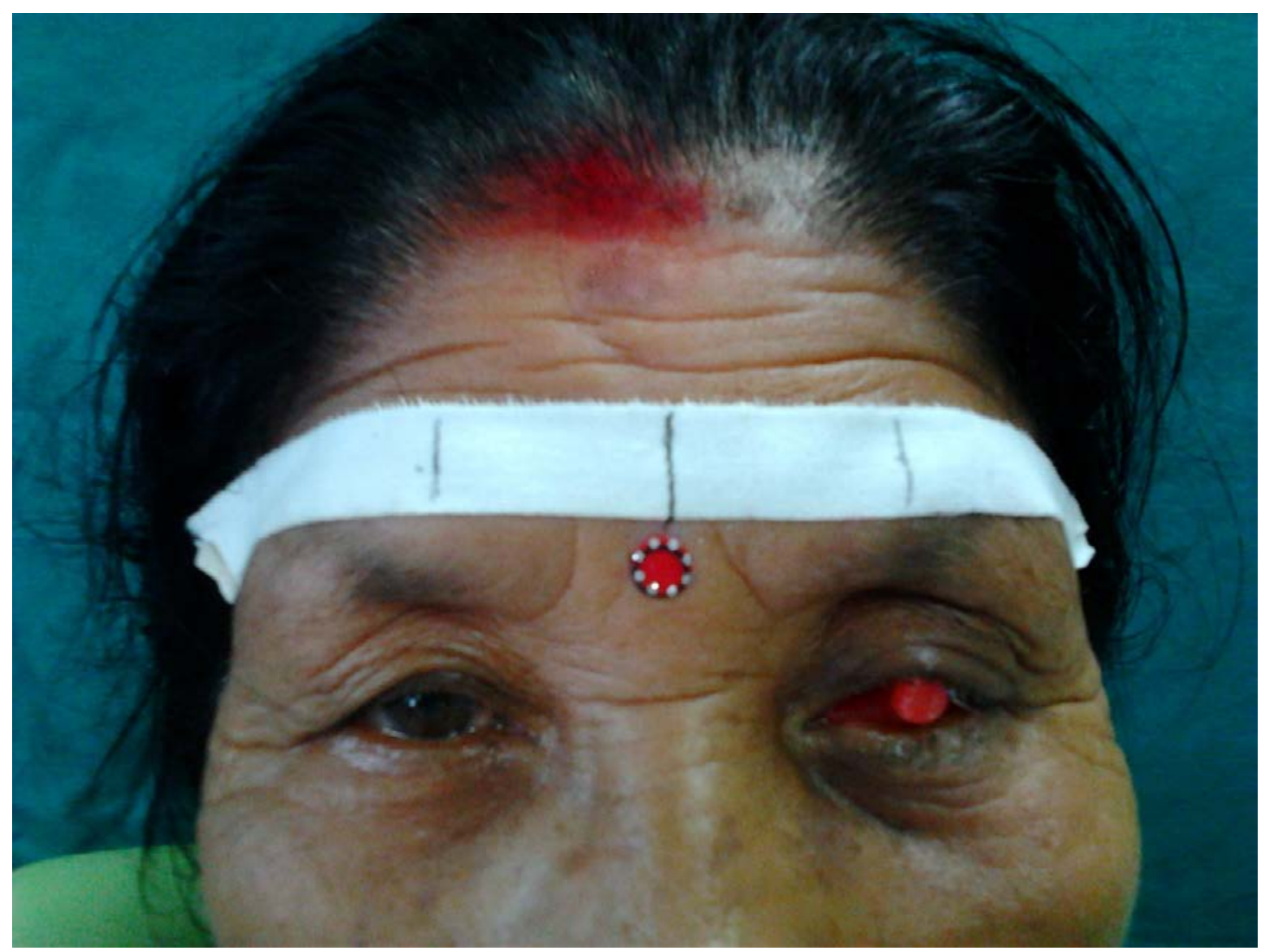

Figure 4. Trial in of wax conformer. Note the tissue tape used for measuring the distance between pupil and vertical midline of nose

\section{Fitting of iris}

The stock eye was trimmed from the periphery to obtain the required size of the iris (Figure 3). It was attached to wax pattern (Figure 5) after cutting the wax to remove a circular chip. After attaching iris properly it was again seated into the socket and verification was done.

7. Fabrication of prosthesis

The wax pattern was flasked in two-part flask using heat polymerizing acrylic resin which was matching to color of sclera and blood vessels were simulated using the red threads from the self cure acrylic resin. The prosthetic iris part was attached with the help of a small self cure stud for its secured position while dewaxing and packing procedure were performed (Figure 6). After complete curing the prosthesis was polished and trimmed. It was inserted into the socket and examined for its cosmetic purposes (Figure 10).

Figure 5. Iris part attached to wax pattern 


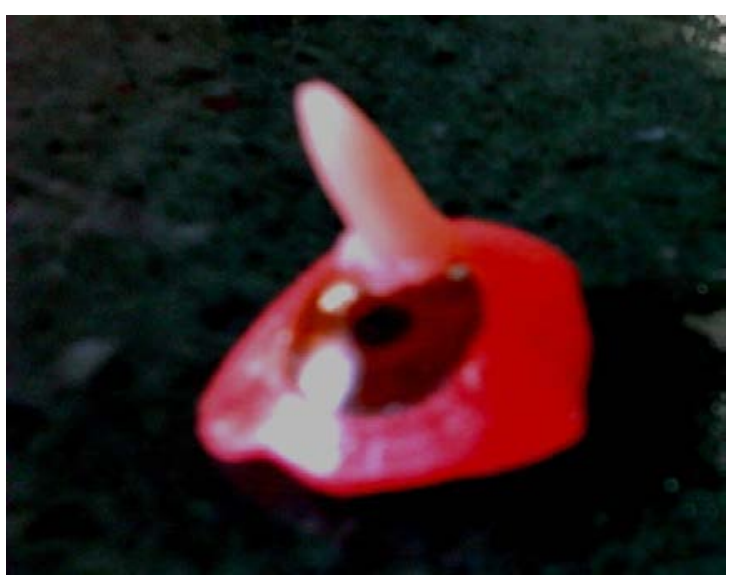

Figure 6. A self cure stud attached to iris part for its secured position during subsequent procedure

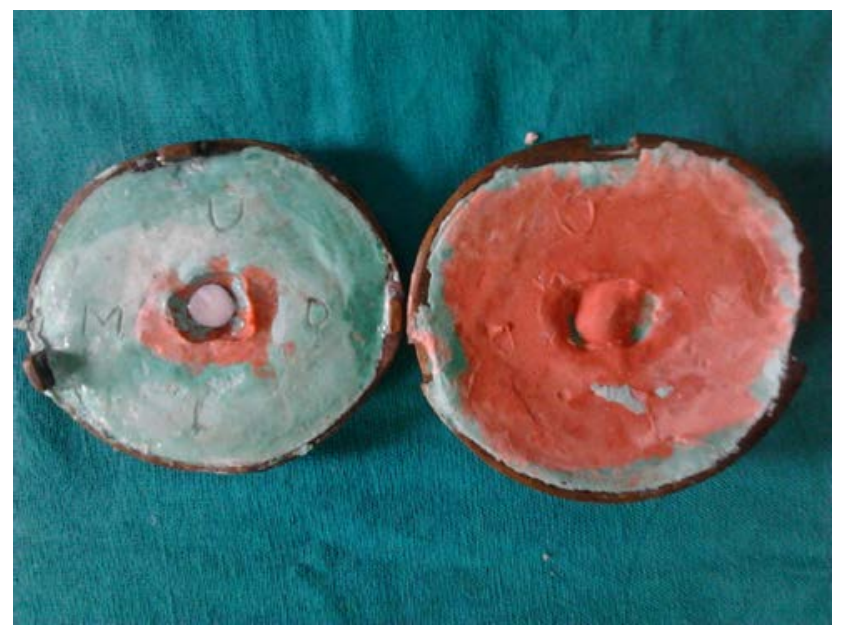

Figure 7. De-waxed two-part flask

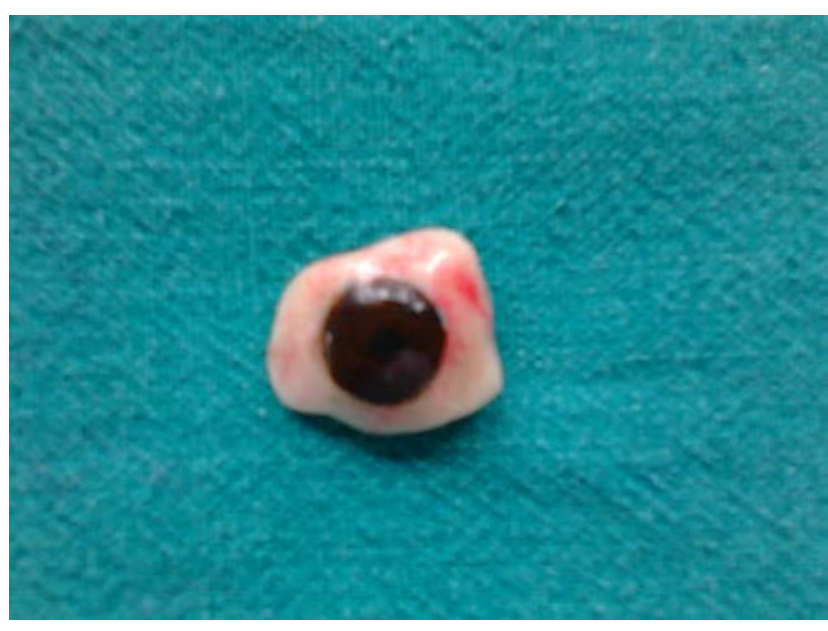

Figure 8. Final prosthetic eye, chameo surface

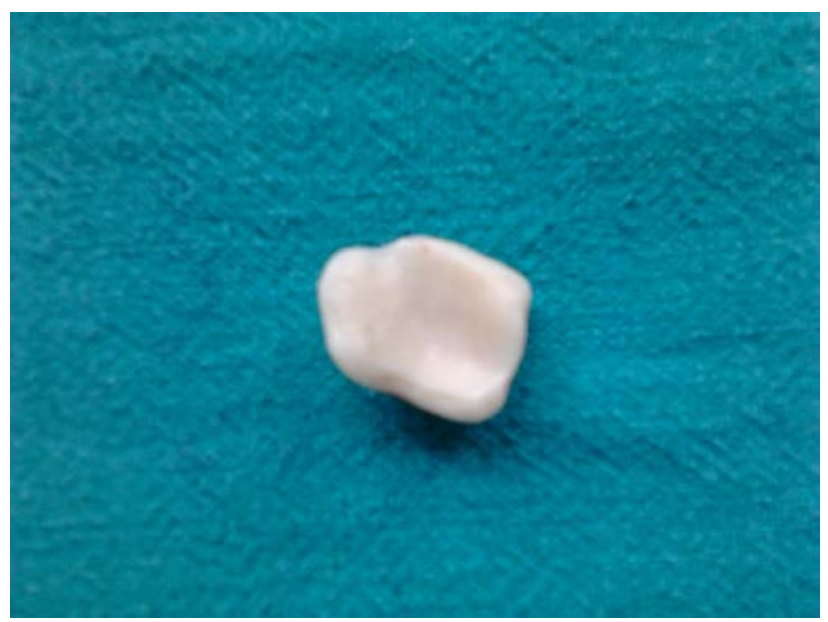

Figure 9. The intaglio surface of prosthesis

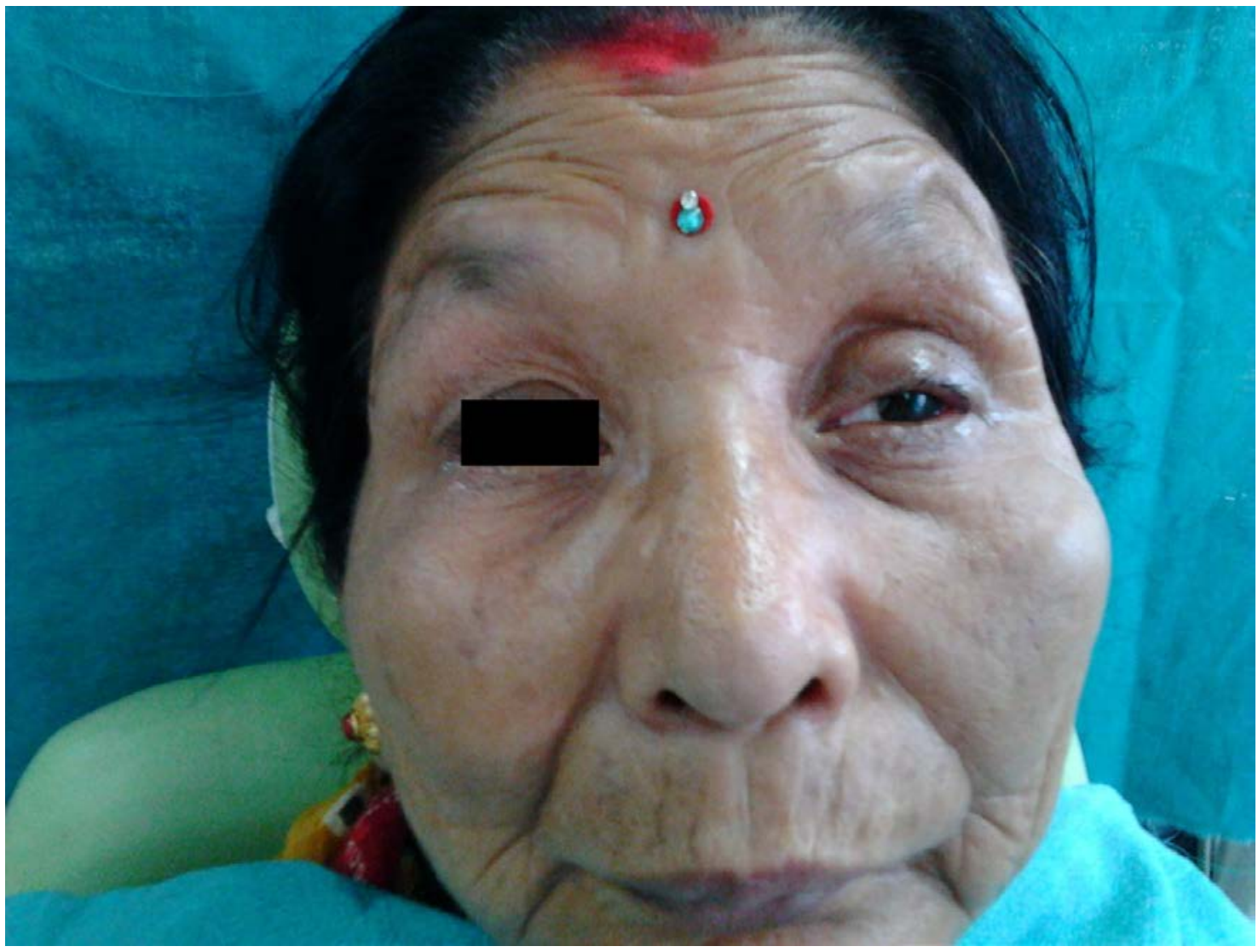

Figure 10. Prosthesis in situ 
Instructions to the patient

The patient was instructed to learn removal and insertion of prosthesis. She was advised to remove the prosthetic eye at least once daily and clean with soft cloth and mild soap. She was advised for follow up for any complications.

\section{Discussion}

The prosthesis met the criteria for its cosmetic outcome but cannot be functional. It was fabricated with easy steps that could be performed in any denture clinic. The alginate impression was used in many case reports $[5,10]$ but lightbody silicone can produce superior impression of the defect in mucostatic manner. There was modified impression technique with fabrication of custom tray or using the stock conformer as a tray described by Allen and Webster [11], however it would require another appointment and though superior impression can be obtained its outcome can be met with adequate scrutiny during wax trial step. While fabricating tray gypsum mold can be utilized using the patient's conformer, it was advised not to use the surgical conformer [12].

The proper steps to make impression and characterization of iris can help the patient to receive benefits of prosthesis. The present case report emphasizes on diligent procedure during these steps.

\section{Conclusion}

Custom made prosthetic eye can encompass the cosmetic demands and even mitigate social and psychological trauma to the patient who have lost their eye permanently.

\section{Acknowledgement}

I would like to acknowledge the patient for her consent for using her photographs for academic purpose. The support of staff of the department was grateful.

\section{References}

[1] Lal S, Schwartz AB, Gandhi T, Moss ML. Maxillofacial prosthodontics for the pediatric patient: "An eye-opening experience”. J Clin Pediatr Dent 2007; 32:5-8.

[2] Guttal SS, Joshi SM, Pillai LK, Nadiger RK. Ocular prosthesis for a geriatric patient with customised iris: A report of two cases. Gerodontology 2011; 28: 152-6.

[3] Raflo GT. Enucleation and evisceration. In: Tasman W, Jarger E, editors. Duane's Clinical Ophthalmology. Vol. 5, 2nd ed. Philadelphia, PA: Lippincott Williams and Wilkins; 1995. p. 1-25.

[4] Artopoulou I, Montgomery CP, Wesley IP, Lemon CJ. Digital imaging in the fabrication of ocular prostheses. J Prosthet Dent 2006; 95: 227-30.

[5] Bartlett SO, Moore DJ. Ocular prosthesis: A physiologic system. J Prosthet Dent 1973; 29: 450-9.

[6] Patil SB, Meshramkar R, Naveen BH, Patil NP. Ocular prosthesis: A brief review and fabrication of an ocular prosthesis for a geriatric patient. Gerodontology 2008; 25: 57-62.

[7] Perman KI, Baylis HI. Evisceration, enucleation and exenteration. Otolaryngol Clin North Am 1988; 21: 171-82.

[8] Brown KE. Fabrication of an ocular prosthesis. J Prosthet Dent 1970; 24(2): 225-35.

[9] Taicher S, Steinberg HM, Tubiana I, Sela M. Modified stock-eye ocular prosthesis. J Prosthet Dent 1985; 54: 95-8.

[10] Welden RB, Niiranen JV. Ocular prosthesis. J Prosthet Dent 1956; 6(2): 272-8

[11] Allen L, Webster HE. Modified impression method of artificial eye fitting. Am J Opthalmol 1969; 67: 189.

[12] Schneider RL. Modified ocular prosthesis impression technique. J Prosthet Dent 1986; 55(4): 482-5. 